studies in this context are needed to provide more insight into the disease process.

\section{References}

1. Kerem E, Conway S, Elborn S, Heijerman H; Consensus Committee. Standards of care for patients with cystic fibrosis: a European consensus. J Cyst Fibros. 2005;4:7-26.

2. Döring G, Hoiby N; Consensus Study Group. Early intervention and prevention of lung disease in cystic fibrosis: a European consensus. J Cyst Fibros. 2004;3:67-91.

3. Sinaasappel M, Stern M, Littlewood J, Wolfe S, Steinkamp G, Heijerman HG, et al. Nutrition in patients with cystic fibrosis: a European consensus. J Cyst Fibros. 2002;1:51-75.

4. Aris RM, Merkel PA, Bachrach LK, Borowitz DS, Boyle MP, Elkin $\mathrm{SL}$, et al. Guide to bone health and disease in cystic fibrosis. J Clin Endocrinol Metab. 2005;90:1888-96.

5. Cystic Fibrosis Trust. Bone mineralisation in cystic fibrosis. http:// www.cftrust.org.uk/aboutcf/publications/consensusdoc/BoneMineral-Booklet.pdf.
6. Conway SP, Morton AM, Oldroyd B, Truscott JG, White H, Smith $\mathrm{AH}$, et al. Osteoporosis and osteopenia in adults and adolescents with cystic fibrosis: prevalence and associated factors. Thorax. 2000;55:798-804.

7. Dif F, Marty C, Baudoin C, de Vernejoul MC, Levi G. Severe osteopenia in CFTR-null mice. Bone. 2004;35:595-603.

8. King SJ, Topliss DJ, Kotsimbos T, Nyulasi IB, Bailey M, Ebeling PR, et al. Reduced bone density in cystic fibrosis: DeltaF508 mutation is an independent risk factor. Eur Respir J. 2005;25:54-61.

9. Shead EF, Haworth CS, Condliffe AM, McKeon DJ, Scott MA, Compston JE. Cystic fibrosis transmembrane conductance regulator (CFTR) is expressed in human bone. Thorax. 2007; 62:650-1.

10. Hardin DF, Arumugam R, Seilheimer DK, LeBlanc A, Ellis KJ. Normal bone mineral density in cystic fibrosis. Arch Dis Child. 2001;84:363-8.

11. Buntain HM, Schluter PJ, Bell SC, Greer RM, Wong JC, Batch J, et al. Controlled longitudinal study of bone mass accrual in children and adolescents with cystic fibrosis. Thorax. 2006; 61:146-54.

12. Caldeira RJ, Fonseca VM, Gomes Junior SC, Chaves CR. Prevalence of bone mineral disease among adolescents with cystic fibrosis . J Pediatr (Rio J). 2008;84(1):18-25.

\title{
The challenge of feeding children to protect against overweight
}

\author{
Shiriki K. Kumanyika, ${ }^{1}$ Kristie J. Lancaster ${ }^{2}$
}

Pediatricians and other health professionals who work with parents of young children have the daunting responsibility of interpreting and communicating guidance about how best to feed children during their development years. Traditionally, the goals in providing such guidance have focused on assuring adequate energy and protein intake, preventing deficiencies of vitamins and minerals and preventing dental disease. However, concepts of optimal child nutrition have been expanded and the challenges of providing appropriate nutritional guidance have increased. This relates both to changes in patterns of nutrition-related disease and to recognition of the role of nutritional factors in the development of diseases throughout the life course. Goals for feeding children now also address considerations related to prevention of chronic diseases, including cardiovascular diseases, cancers, and mental disorders - conditions for which the origins may begin very early in life even when diagnosis does not occur until adulthood. ${ }^{1}$ Important concerns include not only what children eat when young but also how the eating habits they develop during childhood may affect what they eat later in life.

Within the realm of chronic diseases, concerns about obesity are particularly compelling. Epidemic levels have already been reported in many countries and are on the horizon for many others. ${ }^{2}$ Food supplies are changing globally, and the availability of foods that are high in calories from fat and sugar but otherwise nutritionally-poor has increased markedly, even

1. PhD. Professor, Department of Biostatistics and Epidemiology and Pediatrics, School of Medicine, University of Pennsylvania, Philadelphia, PA, USA.

2. PhD. Associate professor, Department of Nutrition, Food Studies \& Public Health, New York University, New York, NY, USA.

No conflicts of interest declared concerning the publication of this editorial.

Suggested citation: Kumanyika SK, Lancaster KJ. The challenge of feeding children to protect against overweight. J Pediatr (Rio J). 2008;84(1):3-6.

doi:10.2223/JPED.1754 
for people with limited incomes. ${ }^{3}$ Moreover, excess energy intake and obesity are occurring in countries where undernutrition and growth stunting are still in evidence. ${ }^{1,4}$ In some cases, the risks of becoming obese are of particular relevance for children who have been undernourished and are stunted. ${ }^{1,5}$

Children with relatively high levels of body fat may seem to be very healthy in comparison to children who are thin and hungry. However, the adverse health consequences of obesity are well documented. They begin in childhood, may last throughout life and may shorten life. ${ }^{6}$ Indeed, adult onset diseases such as diabetes and hypertension are being seen increasingly in children. Understanding how to appropriately feed children in order to prevent or curb the development of obesity is, therefore, of extremely high clinical and public health importance. This understanding must be expressed in terms of potential food choices, feeding regimens, and food program policies.

In their article in this issue, Kranz et al. ${ }^{7}$ focus our attention on feeding children in the 2 to 5 year age range - examining how well the children's dietary intakes fit with current guidelines for optimal nutrition, using the concept of "dietary quality," and how levels of being overweight or at risk for overweight differ according to their definition of dietary quality. These authors use the American terminology in which children in the highest category ( $\geq 95$ th percentile) of the body mass index (BMI) growth charts are termed "overweight," rather than obese, and "at risk for overweight" is between the 85 th and 95th percentiles. They analyze data that are representative of 2 to 5 year old children in the American population using national survey data collected in 1999 through 2002. The data set used has the advantage of including highly standardized height and weight measurements on which to base determinants of weight status. In addition, the parental reports of the children's dietary intake were collected with rigorous interview protocols and subjected to detailed analyses of nutritional content.

As already noted, the multiple considerations for defining dietary quality involve both adequacy and excess. The analyses presented by Kranz et al. draw upon their prior work to develop and then update a comprehensive index tailored by age and gender for children in the 2 to 5 year age range, the Revised Diet Quality Index for Children (RC-DQI), and incorporating the spectrum of relevant dietary constituents. ${ }^{8}$ The 13 components of the index include six key food groups, iron and protective fatty acids, two components associated with consumption of excess calories, and another item that attempts to characterize energy balance. Summing ratings over all components yields a score with a maximum value signifying that the day's food intake meets, on average, all guidelines for what 2 to 5 year old children should eat.
The most important finding is that dietary quality - as defined by Kranz et al. - can be related to children's weight status. From the figure in their article, the gradient of lower prevalence of overweight at higher levels of dietary quality appears to be clearest for the children who are in the at-risk range but have not yet crossed over the threshold to overweight. The association of dietary quality with being in the overweight category is unclear. It is possible that dietary quality has a greater role in weight status within the at-risk range rather than after children are already overweight.

Also important is the finding that relatively few 2 to 5 -year-old Americans are meeting all current guidelines. There were only three of the 13 criteria in the RC-DQI for which at least $2 / 3$ of the children had the maximum possible scores. Thus, even in a country with an oversupply of food, the consumption of an adequate and appropriate mix of foods and protective nutrients is far from assured. In fact, dietary quality may be compromised especially in a country with an oversupply of food given that: 1) food products that are not in line with dietary guidelines are among those most heavily marketed to children and parents, and 2 ) there is a dearth of effective, competitive promotion of the types of foods emphasized in dietary guidelines. ${ }^{9}$

The finding that Mexican-American children had the best dietary quality scores overall is particularly noteworthy because Mexican Americans are socially and economically disadvantaged relative to American non-Hispanic whites. This is apparently not a general finding for ethnic minority populations. The advantageous dietary quality among MexicanAmerican children is quite distinct from the findings in nonHispanic blacks. It is also independent of family income level except that it appears to be most prominent in the lowincome population stratum.

Relatively better dietary quality in Mexican Americans (adults and children) was reported based on earlier analysis of the National Health and Nutrition Examination Survey (NHANES) data using the Healthy Eating Index (HEI), a dietary quality score that was based on the prior American Food Guide Pyramid. ${ }^{10}$ Scores among Mexican Americans were better compared to non-Hispanic whites and blacks for fruits, total fat and sodium and better compared to nonHispanic whites for saturated fat. Overall scores were best for people born in Mexico. The apparent persistence of certain protective dietary practices among Mexican Americans suggests maintenance of traditional preferences and less adoption of some typical American dietary patterns. As noted by Kranz et al. in their interpretation of this finding, benefits of the more plant-based Mexican American dietary pattern may be applicable to a wide range of populations in Latin America and elsewhere. 
Table 1 - Prevalence of at risk of overweight and overweight* in 2 to 5 year old children in three race/ethnic groups (USA, 2003-2004)

\begin{tabular}{lcc}
\hline & At risk of overweight (\%) & Overweight (\%) \\
\hline Males & & 13.0 \\
Non-Hispanic white & 13.6 & 9.7 \\
Non-Hispanic black & 11.3 & 23.2 \\
Mexican American & 15.1 & 10.0 \\
Females & & 16.3 \\
Non-Hispanic white & 13.5 & 15.1 \\
Non-Hispanic black & 10.7 & 11.6 \\
Mexican American & & \\
\hline
\end{tabular}

* At risk of overweight is defined as body mass index (BMI) at or above the 85th percentile and below the 95 th
Control sex-specific BMI-for-age growth charts. Overweight is at or above the 95 th percentile (Ogden et al. ${ }^{11}$ ).

Notwithstanding this positive finding about dietary quality in Mexican Americans, the prevalence of overweight and at risk for overweight in the NHANES data is as high or higher in Mexican American 2 to 5 year olds compared to their nonHispanic white and non-Hispanic black peers (Table 1 ). ${ }^{11}$ The data in the Table are based on the most recent data available for children in the USA, but reflect the pattern observed in data for the period analyzed by Kranz et al. These data suggest that energy balance is not better among Mexican American children, on average, and may in fact be less favorable from an obesity prevention perspective. Direct exploration of the links between dietary quality and weight status in Mexican American children is needed to resolve this apparent discrepancy.

A full understanding of the link between dietary quality and the development of overweight will require longitudinal assessments to determine whether children with better dietary quality are protected from excess weight gain. However, from a practical perspective, these cross sectional data suggest that children who are at risk for overweight are less likely than children in the healthy weight range to meet dietary guidelines. This implies a need for interventions to improve the dietary quality of overweight children in particular.

The application of insights from these data outside of the USA will be influenced by the comparability of the relevant dietary guidance issues for the population in question. The underlying concepts of optimal nutrition, while universal in some respects, are modified by specific societal and cultural contexts, including the types and quantities of foods available, typical food preferences, and other circumstances that relate to how children are fed. ${ }^{12}$ In addition, although the prevalence of underweight in children is not currently of public health concern in the USA, it is still a concern in many countries. This reminds us of how challenging it is to provide guidance that will foster optimal feeding of children under all risk circumstances.

\section{References}

1. Uauy R, Albala C, Kain J. Obesity trends in Latin America: transiting from under- to overweight. J Nutr. 2001;131:893S899S.

2. Wang $Y$, Lobstein $T$. Worldwide trends in childhood overweight and obesity.Int J Pediatr Obes. 2006;1:11-25.

3. Popkin BM. Global nutrition dynamics: the world is shifting rapidly toward a diet linked with noncommunicable diseases. Am J Clin Nutr. 2006;84:289-98.

4. Kelishadi R. Childhood overweight, obesity, and the metabolic syndrome in developing countries. Epidemiol Rev. 2007;29:6276.

5. Fernald LC, Neufeld LM. Overweight with concurrent stunting in very young children from rural Mexico: prevalence and associated factors. Eur J Clin Nutr. 2007;61:623-32.

6. Daniels SR. The consequences of childhood overweight and obesity. Future Child. 2006;16(1):47-67. http:// www.futureofchildren.org/usr_doc/03_5562_daniels.pdf Retrieved on 2007, Dec 6.

7. Kranz S, Findeis JL, Shrestha SS. Use of the Revised Children's Diet Quality Index to assess preschooler's diet quality, its sociodemographic predictors, and its association with body weight status. J Pediatr (Rio J). 2008;84(1):26-34. 
8. Kranz S, Hartman T, Siega-Riz AM, Herring AH. A diet quality index for American preschoolers based on current dietary intake recommendations and an indicator of energy balance. J Am Diet Assoc. 2006; 106:1594-604.

9. Committee on Food Marketing and the Diets of Children and Youth, J. Michael McGinnis, Jennifer Appleton Gootman, Vivica I. Kraak, Editors. Food marketing to children and youth: threat or opportunity? Washington, DC: National Academies Press, 2006.

10. Basiotis PP, Carlson A, Gerrior SA, Juan WY, Lino M. The Healthy Eating Index: 1999-2000. U.S. Department of Agriculture, Center for Nutrition Policy and Promotion. CNPP-12. 2002.

11. Ogden CL, Carroll MD, Curtin LR, McDowell MA, Tabak CJ, Flegal $\mathrm{KM}$. Prevalence of overweight and obesity in the United States, 1999-2004. JAMA. 2006;295:1549-55.
12. World Health Organization. Preparation and Use of Food Based Dietary Guidelines. Report of a joint FAO/WHO consultation Nicosia, Cyprus. Geneva: World Health Organization; 1996. http://www.fao.org/DOCREP/x0243e/x0243e00.htm Retrieved on 2007, Dec 6.

Correspondence:

Shiriki K. Kumanyika

Department of Biostatistics and Epidemiology

University of Pennsylvania School of Medicine

8th floor, Blockley Hall

423 Guardian Drive

19104-6021 - Philadelphia, PA - USA

Tel.: +1 (215) 898-2629

Fax: +1 (215) 573-5311

E-mail: skumanyi@mail.med.upenn.edu

\title{
"Doctor, I think my baby is in pain": the assessment of infants' pain by health professionals
}

\author{
Marie-Claude Grégoire, ${ }^{1}$ G. Allen Finley ${ }^{2}$
}

It was not that long ago that some health professionals did not believe infants could feel pain. Infants were not always given analgesics in the postsurgical period and sometimes during the surgery itself. Pain was not recognized as an important treatable symptom, and therefore was rarely assessed. It was only during the 1980's that clinicians and researchers started to measure the impact of pain assessment and treatment in infants. ${ }^{1}$ Despite these research advances, it took years before pain assessment and treatment in infants became generalized, and unfortunately, they are not yet universal today in the medical world.

Parents, on the other hand, have known for ages that their young children can suffer pain. The article by Elias et al., ${ }^{2}$ in this issue of the Jornal de Pediatria, illustrates well this disagreement between parents and health professionals. The most interesting finding of this study, performed in a nonacute pain situation, is that the agreement between parents and health professional was better in extreme situations, where pain was obviously present or absent, and decisions about treatments were not in doubt. It is in that gray zone of moderate pain that the disagreement was the most important, the zone where a few points higher or lower on the visual analogue scale (VAS) will make a difference between using an analgesic medication or not. Of this disagreement, only $10 \%$ could be explained by factors inherent to babies, leaving a large proportion of the difference of opinion to factors related to the person assessing the pain and to the context surrounding the assessment. This is not surprising, in a situation where the pain is not what the infant says, but what the parent or health professional says.

Disagreement between parents and health care professionals has been shown in the past for infants and toddlers, ${ }^{3}$ but also between health professionals ${ }^{4}$ and between children and parents. ${ }^{5}$ Using a VAS as a global pain assessment score by proxy may increase the risk of disagreement. The VAS is an observational scale in which each observer uses a collection of behavioral cues, which they interpret in the context of their own experience. In particular, the meaning of the anchor

1. MD, MSc, FRCPC. Dalhousie University, Halifax, Nova Scotia, Canada.

2. MD, FRCPC, FAAP. Dalhousie University, Halifax, Nova Scotia, Canada.

No conflicts of interest declared concerning the publication of this editorial.

Suggested citation: Grégoire M-C, Finley GA. "Doctor, I think my baby is in pain”: the assessment of infants' pain by health professionals. J Pediatr (Rio J). 2008;84(1):6-8

doi:10.2223/JPED. 1753 